\title{
Transformative Citizenship Education and Intercultural Sensitivity in Early Adolescence
}

\author{
Jennifer M. Mellizo ${ }^{1, *}$ \\ ${ }^{1}$ University of Wyoming Laboratory School, Laramie, WY, USA \\ *Correspondence: University of Wyoming Laboratory School, University of Wyoming, Laramie, WY, USA. Tel: \\ 1-307-343-3352. E-mail: jmellizo@acsd1.org
}

Received: May 28, 2018

Accepted: June 14, $2018 \quad$ Online Published: June 25, 2018

doi:10.5430/wje.v8n3p139

URL: https://doi.org/10.5430/wje.v8n3p139

\begin{abstract}
As our world continues to evolve into an increasingly diverse, interconnected, and interdependent global society, it is becoming more important for tomorrow's citizens (today's early adolescent students) to develop the knowledge, skills, and dispositions they will need to understand and communicate with individuals who come from many diverse cultural backgrounds. Yet, relatively few researchers have examined the effects of specific curriculum interventions, strategies, and/or educational approaches designed to improve intercultural knowledge, skills, and attitudes during early adolescence. In this study, a causal-comparative quantitative research design was used to explore differences in intercultural sensitivity between a group of 4th-6th grade students at a school that embraces a transformative approach to citizenship education (School 1), and a group of students at a comparison school (School 2). An independent $t$-test revealed students at School 1 scored significantly higher than students at School 2 on a quantitative measure of intercultural sensitivity (AISI). These results suggest a transformative approach to citizenship education can promote the development of intercultural sensitivity during early adolescence. In light of these results, several key aspects of this particular school's transformative citizenship curriculum are discussed in detail.
\end{abstract}

Keywords: citizenship education, social justice, intercultural sensitivity, intercultural education, global citizenship, empathy education

\section{Introduction}

As our world continues to evolve into an increasingly interconnected and interdependent global society, it is becoming more important for tomorrow's citizens (today's early adolescent students) to develop the knowledge, skills, and dispositions they will need to understand and communicate with individuals who come from many diverse cultural backgrounds (Sinicrope, Norris, \& Watanabe, 2007). Teachers naturally assume some responsibility for ensuring today's young people develop the tools they will need to thrive in a diverse, ever-changing world. Yet, best practices in this area have not yet been identified, since relatively few researchers have examined the effects of specific curriculum interventions, strategies, and/or educational approaches intended to cultivate intercultural knowledge, skills, and attitudes during early adolescence. Although educational scholars assert the building blocks for high levels of intercultural competence are most likely established during childhood and adolescence (Dovigo \& Favella, 2012), most research in this area continues to focus on college students and adults.

\subsection{Purpose and Research Question}

The purpose of this study was to contribute to the limited body of research available regarding educational approaches, interventions, and environments that effectively promote intercultural development during early adolescence. Specifically, a causal-comparative quantitative research design was used to explore differences in levels of intercultural sensitivity between $4^{\text {th }}-6^{\text {th }}$ grade students at two different public schools in the Rocky Mountain region of the United States. The following research question was identified:

Is there a difference in levels of intercultural sensitivity between a group of $4^{\text {th }}-6^{\text {th }}$ grade students $(n=73)$ who attend a school that engages in transformative citizenship education (School 1) and a group of $4^{\text {th }}-6^{\text {th }}$ grade students $(n=65)$ who attend a comparison school (School 2), as measured by the Adapted Intercultural Sensitivity Index (AISI)? 


\subsection{Theoretical Framework}

Within the present study, the term intercultural sensitivity refers to the underlying worldview (comprised of knowledge, attitudes, and behavior) that informs an individual's response when he/she encounters cultural difference (Bennett, 1993; 2004). According to Bennett's work, intercultural sensitivity and intercultural competence are related, but not synonymous terms. Whereas the term intercultural competence refers to an individual's "ability to think and act in interculturally appropriate ways", the term intercultural sensitivity describes the individual's ability to "discriminate and experience cultural differences" in ways that are either more or less complex (Hammer, Bennett, \& Wiseman, 2003, p. 422). Bennett (2004) argues high levels of intercultural sensitivity create the potential for high levels of intercultural competence.

\subsubsection{The Developmental Model of Intercultural Sensitivity (DMIS)}

Bennett (1993) hypothesized educational efforts designed to help individuals develop higher levels of intercultural sensitivity would be more successful if they were informed by a clear and specific framework, based upon "some typical progression of development in learners" (p. 22). Through a grounded theory approach, he developed the Developmental Model of Intercultural Sensitivity (DMIS): A constructivist framework that describes a set of stages that many people pass through as they experience intercultural worldview changes and begin to experience cultural difference in in increasingly complex ways $(1993 ; 2004)$. Bennett hoped this framework would help educators develop specific curricula and instructional strategies that would facilitate growth towards higher levels of intercultural sensitivity.

The DMIS framework is comprised of six distinct stages, which represent different intercultural worldview orientations (Bennett, 1993; 2004). At its core, this model assumes exposure to cultural difference (in various forms) can provide the pressure needed for intercultural worldview changes to occur. Each DMIS stage is associated with several issues that must be resolved before an individual can move concretely into the next stage. Bennett (2004) acknowledges occasional retreats are possible, but contends movement through the continuum is generally unidirectional. At the most basic level, the DMIS stages are grouped into two categories based on whether an individual's overarching worldview is ethnocentric or ethnorelative.

The first three stages in the DMIS continuum are considered ethnocentric because individuals' attitudes, thoughts, and actions are "based on the assumption that their worldview is superior" (Olson \& Kroeger, 2001, p. 119). In the first stage, Denial, individuals are not interested in cultural difference, and therefore do not really experience it at all (Bennett, 2004). Individuals in Defense react to the perceived threat of other cultures by denigrating them and/or asserting their own culture's superiority (Sinicrope et al., 2007). In the Minimization stage, individuals "acknowledge cultural differences on the surface" but minimize them, since they "consider all cultures fundamentally similar" (Sinicrope et al., 2007, p. 9).

According to Bennett (2004), ethnorelativism is "the opposite of ethnocentrism-the experience of one's own beliefs and behaviors is just one organization of reality among many viable possibilities" (p. 62). Within the first ethnorelative stage, Acceptance, individuals accept and respect cultural differences related to behavior and values. Individuals who experience Adaptation demonstrate the ability to shift their frame of reference by showing empathy, and develop enhanced intercultural communication skills (Bennett, 2004). When individuals reach the final DMIS stage, Integration, they shift "in and out of different cultural worldviews... without losing themselves...because they define their identities in terms of perspective-shifting and bridge-building" (p. 72).

\subsection{Literature Review}

Thus far, most research in the area of intercultural sensitivity has been conducted with college students and adults. Within educational contexts, several researchers have studied the impact of certain educational initiatives and approaches, such as study abroad experiences and international school attendance, on university and high school students' levels of intercultural sensitivity. Straffon (2003) found a significant positive relationship between length of time spent at an international high school in Malaysia and level of intercultural sensitivity, according to Bennett's DMIS framework. Engle \& Engle (2004) reported college students demonstrated significantly higher levels of intercultural sensitivity after participating in a long-term study abroad program. Williams (2005) found college students who studied abroad demonstrated significantly higher levels of intercultural sensitivity than college students who remained on an American campus, and Walton et al. (2015) found short cultural immersion experiences had a positive impact on high school students' levels of intercultural understanding.

The results of several research studies indicate early adolescent students also possess the capacity to experience cultural difference from ethnorelative perspectives (Holm et al., 2009; Mellizo, 2017; Pederson, 1997; Ruokonen \& 
Kairafuoiri, 2012), yet only a handful of researchers have explored the impact of specific educational initiatives on the intercultural sensitivity levels of students within this age range. Ngai \& Koehn (2010) found that $\mathrm{K}-5^{\text {th }}$ grade students at a primary school in Montana, USA developed "new appreciation for, and interest in diverse peoples and issues by directly experiencing the local context in which diversity resides" (p. 604). In their study, students were exposed to a "two-year place-based intercultural approach to indigenous education" (p. 597) that provided them with increased opportunities to directly interact with and learn from people from several local American Indian tribes. Dovigo \& Favella (2012) reported 10-14 year-old students in Italy demonstrated significantly higher levels of intercultural sensitivity after participating in a creative art-based curriculum project. Mellizo (2016) found that $4^{\text {th }}-8^{\text {th }}$ grade students in Wyoming, USA demonstrated significantly higher levels of intercultural sensitivity after participating in a culturally diverse music curriculum intervention based on the traditional music of the Fon people in Benin, West Africa. The results of these studies indicate that certain curricular experiences have potential to cultivate higher levels of intercultural sensitivity and understanding during early adolescence, although more research is clearly needed in this area.

\section{Method}

\subsection{Participants}

The participants in the present study were 138 early adolescent students at two different public schools in the Rocky Mountain region of the United States. Students at both School 1 and School 2 ranged from $9-12$ years old $\left(4^{\text {th }}-6^{\text {th }}\right.$ Grade). The breakdown of student participants by gender and grade level is shown in Table 1.

Table 1. Student Demographic Information Broken Down by Gender and Grade Level $(n=138)$

\begin{tabular}{lllllll}
\hline & \multicolumn{3}{c}{ Gender } & \multicolumn{2}{c}{ Grade } & Total \\
\cline { 2 - 7 } & Male & Female & $4^{\text {th }}$ & $5^{\text {th }}$ & $6^{\text {th }}$ & \\
\hline School 1 & 40 & 33 & 24 & 25 & 24 & 73 \\
School 2 & 23 & 42 & 20 & 23 & 22 & 65 \\
Total & $\mathbf{6 3}$ & $\mathbf{7 5}$ & $\mathbf{4 4}$ & $\mathbf{4 8}$ & $\mathbf{4 6}$ & $\mathbf{1 3 8}$ \\
\hline
\end{tabular}

The student participants at School 1 and School 2 share many similarities related to age, locale, school size, academic test scores, and ethnic diversity. However, the underlying missions/visions of the public schools they attend differ in subtle, yet important ways. School 1's vision statement explicitly highlights a commitment to developing competent and democratic citizens in a diverse and ever-changing world. Additionally, School 1's mission statement stresses continuous improvement towards high levels of both academic and social achievement. In contrast, School 2's mission/vision statement clearly prioritizes academic achievement and personal growth, and does not explicitly mention citizenship or social learning as educational goals.

\subsection{Transformative Citizenship Education}

The teachers at School 1 embrace a transformative approach to citizenship education. According to Banks, transformative citizenship education is a specific form of citizenship education intended to help students "develop the knowledge, attitudes, and skills needed to function within their nation-states and regions, as well as in a global society" (2013, p. 112). Transformative citizenship education differs from the mainstream approach to citizenship education still present in many United States classrooms, which prioritizes national citizenship and focuses primarily "on helping students to develop national loyalty, commitment, and allegiance to the nation-state" (p. 112). Banks (2015) contends this mainstream approach is insufficient because it "reinforces the status quo and the dominant power relationships in society" (p.36), and fails to "help students to understand their multiple and complex identities or the ways in which their lives are influenced by globalization, or what their role should be in a global world" (p. 37). In contrast, a transformative approach to citizenship education requires critical engagement on the part of the students, and encourages them to "identify problems within society, acquire knowledge related to their home and community cultures and languages, identify and clarify their values, and to take thoughtful individual or collective civic action that will improve the human condition" (p. 112).

\subsubsection{Multiple Citizenship Identifications}

Unlike the mainstream approach to citizenship education in the United States, which prioritizes citizenship from a national perspective, transformative citizenship education stresses positive and reflective citizenship identifications 
and attachments at multiple levels (including cultural, national, regional, and global). Banks (2015) contends these identifications are developmental in nature. He clarifies,

An individual can attain a healthy and reflective national identification only when he or she has acquired a healthy and reflective cultural identification; and individuals can develop reflective and positive global identifications only after they have a realistic, reflective, and positive national identification. (p. 37)

Figure 1 is a visual depiction of the multiple layers of citizenship identifications that the teachers at School 1 aim to cultivate through their transformative citizenship curriculum, beginning in the center with the individual him/herself, and extending outward towards a clarified, positive, and reflective global identification.

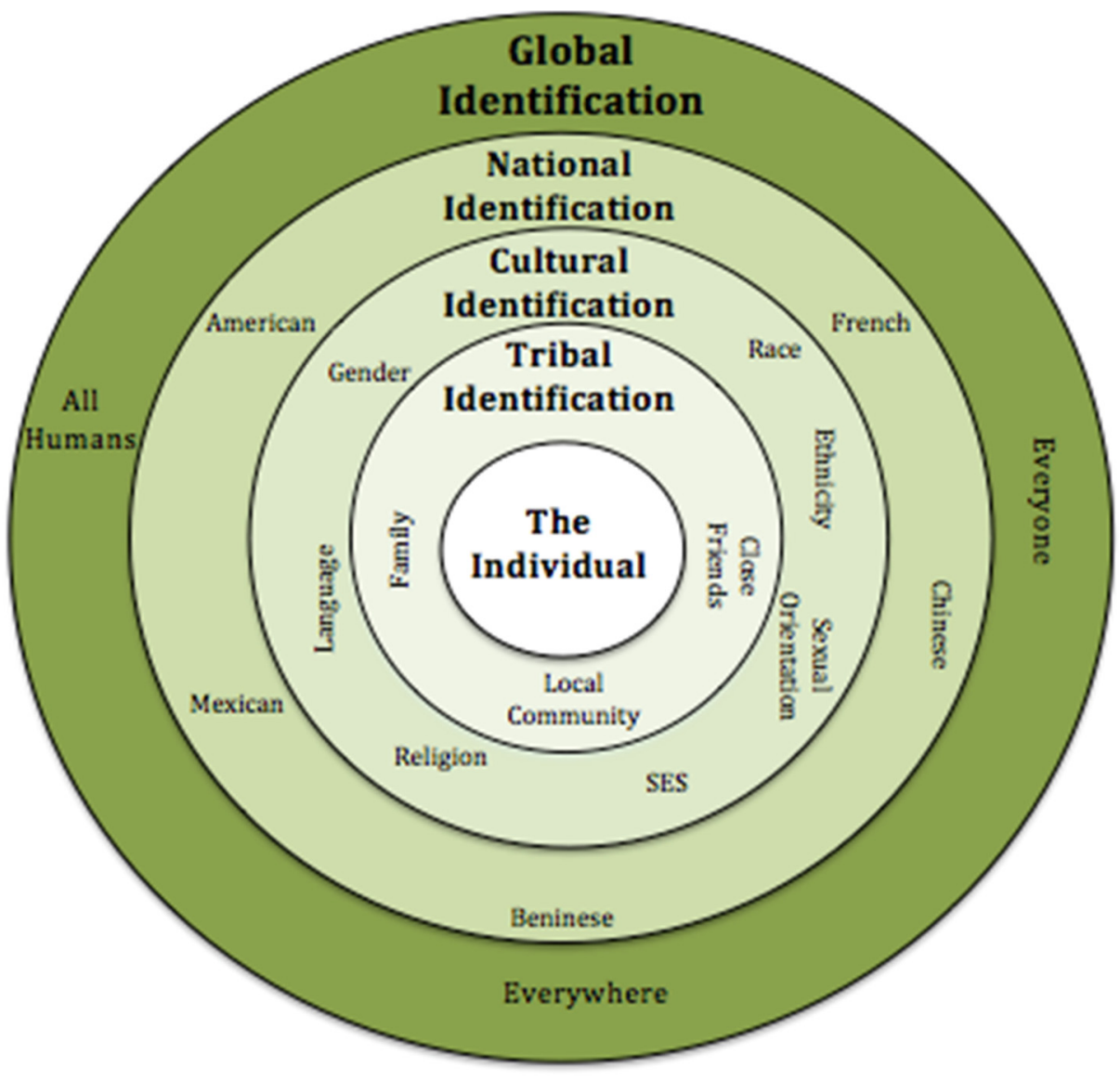

Figure 1. School 1's Conceptualization of Transformative Citizenship Education

\subsection{Instrument and Data Collection}

\subsubsection{Adapted Intercultural Sensitivity Index (AISI)}

Student levels of intercultural sensitivity were assessed through the Adapted Intercultural Sensitivity Index (AISI). This quantitative instrument is an adapted version of the Intercultural Sensitivity Index (ISI), developed by Olson and Kroeger in 2001. Because the original ISI was written for adults, Mellizo (2016) adapted the wording of ISI statements so students within the $4^{\text {th }}-8^{\text {th }}$ grade range could easily understand them. Four practicing $4^{\text {th }}-8^{\text {th }}$ grade classroom teachers reviewed the adapted statements, made suggestions, and verified they were worded in ways that would be understood by students in this age group, while maintaining their original intent (Mellizo, 2016). The final version of the AISI instrument contained 37 items, each of which corresponded to a specific DMIS stage (Denial $=7$ items, Defense $=7$ items, Minimization $=6$ items, Acceptance $=8$ items, Adaptation $=4$ items, and Integration $=5$ items). Students used the following Likert-type scale to indicate their level of agreement with each statement: Strongly Agree (5), Agree (4), I don’t know (3), Disagree (2), Strongly disagree (1).

Cronbach's Alpha was used to investigate the internal consistency of the AISI. Mellizo(2016) used this instrument 
for both a pre- and post-test, and found it demonstrated an acceptable level of internal consistency on both occasions $(\alpha=.76$ on the pre-test; $\alpha=.82$ on the post-test). Within the present study, the overall AISI instrument again demonstrated an acceptable level of internal consistency, $\alpha=.82(\alpha=.79$ for the ethnocentric subset; $\alpha=.76$ for the ethnorelative subset).

Correlations between AISI subsets helped to establish construct validity, providing evidence that this instrument was compatible with the underlying theoretical framework (Bennett's DMIS). As shown in Table 2, all ethnorelative subsets (Acceptance, Adaptation, and Integration) were significantly associated with one another $(p<.05)$ and with the overall AISI score. Additionally, all ethnocentric subsets (Denial, Defense, and Minimization) were significantly associated with one another, and negatively associated with the overall AISI score. Minimization was significantly related to Denial and Defense, but was not significantly negatively associated with the ethnorelative stages. This finding is consistent with Bennett's argument that although Minimization is theoretically ethnocentric, it is a transitional stage (2004).

Table 2. Correlations between Individual DMIS Subsets and Overall AISI Score

\begin{tabular}{lllllll}
\hline Variables & Den. & Def. & Min. & Accept. & Adapt. & Int. \\
\hline Denial & & & & & & \\
Defense & $.505^{*}$ & & & & & \\
Minimization & $.336^{*}$ & $.169^{*}$ & & & & \\
Acceptance & $-.309^{*}$ & $-.476^{*}$ & -.085 & & & \\
Adaptation & $-.260^{*}$ & $-.318^{*}$ & -.097 & $.479^{*}$ & & \\
Integration & $-.213^{*}$ & -.137 & .132 & $.427^{*}$ & $.504^{*}$ & \\
Overall AISI & $-.767^{*}$ & $-.684^{*}$ & $-.335^{*}$ & $.646^{*}$ & $.672^{*}$ & $.618^{*}$ \\
\hline
\end{tabular}

* Indicates correlation was significant at the $\mathrm{p}<0.05$ level.

\subsection{Data Analysis}

Mean scores for each DMIS subset were calculated for each participant. These subset scores were used to calculate an overall, continuous AISI score for each student participant. The continuous scores had a hypothetical range of 1-49. A hypothetical score of "1" occurred if a participant indicated a "1" level of agreement (Strongly Disagree) with all statements from ethnorelative stages, and a "5" level of agreement (Strongly Agree) with all statements from ethnocentric stages. A hypothetical score of " 49 " occurred if a participant indicated a " 5 " level of agreement (Strongly Agree) with all statements from ethnorelative stages, and a "1" level of agreement (Strongly Disagree) with all statements from ethnocentric stages. An independent $t$-test was used to determine whether there was a difference in AISI score between students at School 1 and students at School 2. The critical level of significance for statistical analyses was set at $p<.05$.

\section{Results}

AISI scores for this sample of $4^{\text {th }}-6^{\text {th }}$ grade students $(n=138)$ ranged from 20.93-42.47. The assumption of normality was confirmed through the Shapiro-Wilks test and visual inspection of histograms and Q-Q plots. An independent $t$-test revealed a statistically significant difference between groups in terms of overall intercultural sensitivity; $t(136)=-3.77, p<.05)$. The mean overall AISI score for School $1(M=31.43, S D=4.19)$ was significantly higher than the mean overall AISI score for School $2(M=28.83, S D=3.82)$. Cohen's effect size value $(d=.62)$ indicated moderate to high practical significance. As shown in Table 3, the mean scores for the School 1 were lower on all ethnocentric subsets and higher on all ethnorelative subsets than School 2. 
Table 3. AISI Results with Subset Means and Standard Deviations

\begin{tabular}{lllll}
\hline & \multicolumn{2}{c}{ School $1(n=73)$} & \multicolumn{2}{c}{ School 2 $(n=65)$} \\
\cline { 2 - 5 } & $M$ & $S D$ & 28.83 & $S D$ \\
\hline Overall AISI & 31.41 & 4.19 & 2.77 & 3.82 \\
Denial & 2.68 & .53 & 2.31 & .56 \\
Defense & 2.21 & .57 & 3.07 & .60 \\
Minimization & 2.94 & .58 & 3.82 & .76 \\
Acceptance & 3.89 & .44 & 3.36 & .54 \\
Adaptation & 3.44 & .43 & 3.16 & .52 \\
Integration & 3.22 & .50 & .47 \\
\hline
\end{tabular}

\section{Discussion}

Within the present study, an independent $t$-test revealed a significant difference in levels of overall intercultural sensitivity between a group of $4^{\text {th }}-6^{\text {th }}$ grade students who attended a school that embodied a transformative approach to citizenship education (School 1) and a comparison group (School 2). Students at School 1 scored significantly higher on the AISI than students at School 2. With regard to individual subset scores, students at School 1 demonstrated lower levels of Denial, Defense, and Minimization, and higher levels of Acceptance, Adaptation, and Integration than students at School 2. These results support the previous work of Ngai \& Koehn (2010), Dovigo \& Favella (2012), and Mellizo (2016), who found curricular initiatives designed to provide early adolescent students with more opportunities to encounter and experience cultural difference resulted in positive social learning outcomes. Specifically, the findings in the present study indicate a transformative approach to citizenship education can promote growth towards higher levels intercultural sensitivity during early adolescence. In light of this result, several unique aspects of School 1's transformative citizenship curriculum will now be examined in more depth.

\subsection{Project Citizen}

During the 2016-2017 school year, students at School 1 participated in Project Citizen: A program that promotes competent and responsible participation in local and state government (http://www.civiced.org/pc-program). At the beginning of the year, teachers planned and facilitated a multidisciplinary unit related to Garbology, which is the "study of modern culture through the analysis of what is thrown away as garbage" (Garbology, n.d.). As the year progressed, students collectively identified and researched several problems related to "garbage" in their local community and subsequently planned and implemented action steps towards solving them. One group of students decided to try to reduce the use of polystyrene products, both in the school and the local community. Ultimately, these students were successful: Their school cafeteria no longer uses polystyrene trays, and several local restaurants switched from polystyrene to-go containers to compostable boxes.

The Project Citizen program provides students with authentic opportunities to engage in the democratic process within their classroom walls. As the learning process unfolds, they are prompted to consider multiple perspectives, communicate with each other in respectful ways, and ultimately find ways come to consensus. Additionally, the Project Citizen program requires students to take "action" of some sort, which Banks (2015) contends is an important component of the transformative approach. The distinct "action" component embedded in Project Citizen helps students discover that their voice matters and they have the power to initiate positive change in the world around them. Past research has shown that students who participate in Project Citizen make significant gains in the areas of civic skills and civic dispositions, and are more committed than comparison students to the rights and responsibilities of democratic citizens (Liou, 2003; Root \& Northup, 2006; Tolo, 1997; Vonce, Metcalf, \& Patrick, 2000).

\subsection{Empathy Education}

Banks (2015) stresses the cultivation of empathy (the ability to put ourselves in the shoes of others) as an important component of citizenship education. He states, "Educators can assist with empathy building by showing students ways to view one's own culture and those of others from multiple perspectives" (p. 264). Greene (1995) is also passionate about the importance of empathy education in schools. She argues one of the most crucial roles of educators is helping students develop the capacity to see through others' eyes through the life-long process of becoming "wide-awake to the world" (p. 4). Bennett (1993) elaborates on the unique relationship between empathy and intercultural skill development. He contends, "Central to any intercultural communication skill is the ability to experience some aspect of reality differently from what is 'given' by one's own culture" (p. 53). 
In 2015, School 1 was named an Ashoka Changemaker School. According to the Ashoka website, changemaker schools "are living models of transformative approaches to education and showcase an incredible range of how-tos that any educator can learn from in her efforts to bring empathy and changemaking more fully inside school walls" (https://www.ashoka.org/en/program/changemaker-schools). Since becoming a part of the Ashoka network, teachers and administrators at this school have fully committed themselves to finding natural ways to imbed empathy education into the school curriculum-at every grade level, and in every subject area. For example, a first/second grade teacher at this school starts each day with a morning meeting, and uses a tool she calls equity sticks to ensure every student in the class has a voice. Down the hallway, the Spanish teacher considers the individual needs of students who do not perform to the best of their ability when constrained to traditional desks and tables, and therefore provides a wide variety of flexible seating options from which they can choose. A middle school homeroom teacher plans an after-school "social justice lock-in", during which the students attend a national level social justice symposium, engage in age-appropriate empathy-building activities, and participate in meaningful conversations about issues of inequity in their community, state, country, and world.

\subsubsection{Global Empathy Building through Imagined Contact}

During the 2015-2016 school year, teachers at School 1 planned and implemented two full days of school-wide integration activities related to the West African country of Benin. During these two days, all K- $8^{\text {th }}$ grade students participated in a wide array of hands-on activities related to every subject area in the school curriculum. Simulation experiences prompted them to "imagine" what might be like to bargain at the market in Benin, carry water for long distances, and wash clothes by hand. These global empathy activities were theoretically informed by the imagined intergroup contact hypothesis, which is based on the argument that "simply imagining intergroup contact with an outgroup member may be enough to elicit more positive intergroup attitudes" (Crisp, Stathi, Turner, \& Husnu, 2009). Since this theory emerged in 2009, "over 70 studies [have shown] that imagining a positive interaction with an outgroup member can reduce prejudice and encourage positive intergroup behavior" (Miles \& Crisp, 2014, p. 3). The positive effects of imagined intergroup contact have been significantly larger in in children than adults, possibly because "children are at a formative stage where imagery is a key component of how they learn about the world" (p. 19).

\subsection{Altruism}

Batson (2008) defines altruism as "a motivational state with the ultimate goal of increasing another's welfare" (p. 3). Students and teachers at School 1 often engage in acts of altruism, according to this definition. In fact, many $5^{\text {th }}-8^{\text {th }}$ grade students belong to a club called "Force of Altruism" (FOA). Members of this student-led club continuously seek out opportunities to take action on behalf of others. During the 2016-2017 school year, members of FOA volunteered for and raised money for "Family Promise"-a community organization dedicated to helping homeless and low-income families achieve sustainable independence. Additionally, they sponsored an overnight community event called "Car City", which was designed to raise awareness about homelessness in their community.

Coon (2000) makes an interesting connection between citizenship identification and altruism. He argues, "People within an in-group feel more altruistic toward other members of the group than they do towards outsiders" (p. 76). Coon hypothesizes there are five distinct levels of altruism, and contends an individual reaches "the fifth level of altruism" when he or she "comes to believe that many millions of people, of varying creeds and colors, are all on his or her team" (p. 86). Individuals who reach this fifth level of altruism are motivated (and in some cases feel obligated) to help ALL people, regardless of geography, race, ethnicity, gender, sexual orientation, language, or religion.

Because the students at School 1 are continuously prompted to develop clarified, positive, and reflective citizenship identifications at multiple levels (see Figure 1), they are motivated to act altruistically on local, regional, national, and global levels. When students plan fundraisers, they often make collective decisions about the charitable organizations they would like to support. During the 2014-2015 school year, the $4^{\text {th }}$ and $5^{\text {th }}$ grade classes planned a "Sweet Shoppe" fundraiser and chose to split their proceeds (almost $\$ 5,000)$ between local, state, national, and global charitable organizations.

\subsection{Short-Term Cultural Immersion}

Students at School 1 also have opportunities to participate in short cultural immersion experiences. During the 2015-2016 school year, $5^{\text {th }}-8^{\text {th }}$ grade students co-planned an international youth summit that brought together youth from nine different countries, including countries of the war-torn former Yugoslavia. Subsequently, twelve students traveled to Croatia for two weeks to attend and facilitate this conference, and to experience life in a different part of the world. Additionally, two middle school students recently had an opportunity to travel to Benin, West Africa to 
complete a service-learning project and learn about musical and cultural traditions. Past researchers have reported short-term cultural immersion experiences and long-term study abroad programs made a positive impact on intercultural sensitivity at the secondary and university level (Engle \& Engle, 2004; Walton et al., 2015; Williams, 2005). However, more research is needed to determine the specific benefits of short cultural immersion experiences at younger ages.

\subsection{Limitations}

An inherent limitation of causal-comparative research is determining causation. Although a group difference does not infer causation, Lodico, Spaulding, \& Voegtle (2006) contend the extent to which the difference "can be used as evidence of a causal relationship depends on both the design of the study and the type of statistical test used to analyze the results" (p. 235). Researchers should therefore take steps to limit the possibility of extraneous variables whenever possible in order to "offer stronger evidence of causation" (p. 236). Within the present study, two potential confounding variables were identified. First, although the two groups of students were similar in many ways (sample size, grade level, locale, academic test scores, ethnic diversity), they differed in terms of gender (see Table 1). School 1 had more male participants, while School 2 had more female participants. Previous researchers have reported gender differences with regard to adolescent intercultural sensitivity, with girls scoring significantly higher than boys (Holm et al., 2007; Mellizo, 2016). Therefore, the fact that the sample of students from School 1 had more boys than the sample of students from School 2 actually strengthens the conclusions drawn in this study.

Additionally, it should be noted that although the two schools represented in this study were similar in terms of ethnic diversity, they differed in terms of socioeconomic status (SES). Forty-six percent of students at School 2 came from low-income families, compared to only twenty percent at School 1. Although it seems reasonable to assume students from high income families would have more opportunities to encounter cultural difference through travel experiences than students from low income families, the extent to which this group difference affected intercultural sensitivity scores in the present study cannot be determined. As such, these results should be interpreted with a degree of caution.

\section{Conclusion}

As educators, we all share the responsibility of helping students become successful, responsible, and productive citizens in an increasingly diverse, interconnected, and interdependent global society. Yet, Banks (2013; 2015) contends many students have not yet developed an awareness of themselves within the greater world-possibly because too much time is spent cultivating national identity within the educational setting. Banks (2015) argues a transformative approach to citizenship education "is needed to help students develop clarified and reflective cultural, national, regional, and global identifications and the knowledge, skills, and commitment needed to take action to make their communities, nations, and world more democratic and just" (p. 37).

Assessing the social learning outcomes related to educational approaches such as transformative citizenship education is challenging, to say the least. For example, one intended outcome of this educational approach is higher levels of cross-cultural competency, yet there is still no clear consensus among educational researchers regarding the ways in which cross-cultural competency should be documented/assessed. Banks himself asserts, "We have not clarified, in any adequate way, the minimal level of cross-cultural competency we consider appropriate and/or satisfactory...nor have we developed valid and reliable ways to assess levels of cross-cultural competency" (2015, p. 58). Furthermore, Banks' notion of transformative citizenship education pushes past goals related to cross-cultural competency towards goals related to social action, relying heavily on the theoretical idea that this type of educational approach cultivates the types of citizens who are willing to actualize their values by taking collective civic action to transform the world around them into a better place. Transformative global citizens are citizens who actively and continuously work to promote ethical principles such as social justice and equality within their communities, nations, and world. More longitudinal research is needed to determine whether this theoretical notion holds up in reality.

Despite these challenges, we must continue to examine viable ways of assessing social learning outcomes that result from educational approaches such as transformative citizenship education. The Developmental Model of Intercultural Sensitivity (DMIS) (and associated quantitative instruments) has potential to provide useful information about the effectiveness of these types of curricular initiatives. This framework considers changes in intercultural knowledge, attitude, and behavior as "manifestations of changes in the underlying worldview" (Bennett, 2004, p. 75). The DMIS model assumes that increased opportunities to explore and experience cultural difference (whether it be through direct, in-direct, or imagined contact) will help learners move from an ethnocentric worldview to a more ethnorelative worldview, creating the potential for them to develop higher levels of cross-cultural communication 
competence in the future.

Within the present study, early adolescent students at a public school that engages in a transformative approach to citizenship education scored significantly higher on a quantitative measure of intercultural sensitivity than students at a comparison school. These results indicate this particular school's transformative approach to citizenship education, which incorporates learning experiences related to civic engagement, empathy education, altruistic action, imagined contact, and cultural immersion, can promote growth towards higher levels of intercultural sensitivity during early adolescence. I hope the specific illustrations of several aspects of this school's transformative approach will help other educators and administrators conceptualize the ways in which intercultural skills related to critical thinking, perspective taking, group identification, cross-cultural communication, decision-making, and collective social action can be naturally imbedded into existing school curricula. Additionally, I hope these examples will serve as a catalyst for new ideas as we continuously conceptualize, implement, and evaluate educational initiatives designed to help young people develop "the skillset and connection to purpose" they will need to "thrive in the modern world and find solutions to our most complex problems" (https://www.ashoka.org/en/program/changemaker-schools).

\section{References}

Banks, J. A. (2013). Group identity and citizenship education in global times. Kappa Delta Pi Record, 49(3), 108-112. https://doi.org/10.1080/00228958.2013.819184

Banks, J. A. (2015). Cultural diversity and education: Foundations, curriculum, and teaching (6 $6^{\text {th }}$ ed.). Boston: Allyn \& Bacon.

Batson, C. D. (2008). Empathy-induced altruistic motivation. Unpublished manuscript, Department of Psychology, University of Kansas.

Bennett, M. J. (1993). Towards a developmental model of intercultural sensitivity. In R. Michael Paige (Ed.), Education for the Intercultural Experience (pp. 21-71). Yarmouth, ME: Intercultural Press.

Bennett, M. J. (2004). From ethnocentrism to ethnorelativism. In J. S. Wurzel (Ed.), Toward Multiculturalism (pp. 62-78). Newton, MA: Intercultural Resource Corporation.

Coon, C. (2000). Culture wars and the global village: A diplomat's perspective. Amherst, NY: Prometheus Books.

Crisp, R. J., Stathi, S., Turner, R. N., \& Husnu, S. (2009). Imagined intergroup contact: Theory, paradigm, and practice. Social and Personality Psychology Compass, 3(1), 1-18. https://doi.org/10.1111/j.1751-9004.2008.00155.x

Dovigo, F., \& Favella. C. (2012). Promoting and evaluating creative art-based projects in intercultural education. Paper presented at ECER, 2012, The Need for Educational Research to Champion Freedom, Education and Development for All. Contribution retrieved from http://www.eera-ecer.de/ecer/programmes/print/conference/6/contributions/16061/

Engle, L., \& Engle, J. (2004). Assessing language acquisition and intercultural sensitivity development in relation to study abroad program design. Frontiers: The Interdisciplinary Journal of Study Abroad, X, 219-236.

Garbology [Def. 1]. (n.d.). In Merriam Webster Online. Retrieved July 31, 2017, from http://www.merriam-webster.com/dictionary/garbology

Greene, M. (1995). Releasing the imagination: Essays on education, the arts, and social change. San Francisco, CA: Jossey-Bass Publishers.

Hammer, M. R., Bennett, M. J., \& Wiseman, R. (2003). Measuring intercultural sensitivity: The intercultural development inventory. International Journal of Intercultural Relations, 27, 421-443. https://doi.org/10.1016/S0147-1767(03)00032-4

Holm, K., Nokelainen, P., \& Tirri, K. (2009). Relationship of gender and academic achievement to Finnish students' intercultural sensitivity. High Ability Studies, 20, 187-200. https://doi.org/10.1080/13598130903358543

Liou, S. M. (2003). The effect of "we the people...project citizen" on the civic skills and dispositions of Taiwanese students. Paper presented at the annual meeting of the American Educational Research Association, Chicago, IL.

Lodico, M. G., Spaulding, D. T., \& Voegtle, K. H. (2006). Methods in educational research: From theory to practice. San Francisco, CA: John Wiley \& Sons, Inc. 
Mellizo, J. M. (2016). Multicultural music education and intercultural sensitivity in early adolescence: A mixed methods study. (Doctoral dissertation). Retrieved from ProQuest. Theses and Dissertation Database. (UMI No. 10116176)

Mellizo, J. M. (2017). Exploring intercultural sensitivity in early adolescence: A mixed methods study. Intercultural Education, 28(4), 1-20. https://doi.org/10.1080/14675986.2017.1392488

Miles, E., \& Crisp, R. J. (2014). A meta-analytic test of the imagined contact hypothesis. Group Processes Intergroup Relations, 17(3), 3-26. https://doi.org/10.1177/1368430213510573

Ngai, P. B., \& Koehn, P. H. (2010). Indigenous studies and intercultural education: The impact of a place-based primary-school program. Intercultural Education, 21(6), 597-606. https://doi.org/10.1080/14675986.2010.533039

Olson, C. I., \& Kroeger, K. R. (2001). Global competency and intercultural sensitivity. Journal of Studies in International Education, 5, 116-137. https://doi.org/10.1177/102831530152003

Pederson, P. V. (1997). Intercultural sensitivity and the early adolescent. Paper presented at the annual meeting of the National Council for the Social Studies, Cincinnati, OH.

Root, S., \& Northup, J. (2006). Project Citizen evaluation report. Denver, CO: RMC Research Cooperation.

Ruokonen, I., \& Kairafuoiri, S. (2012). Intercultural sensitivity of the Finnish ninth graders. Procedia Social and Behavioral Sciences, 45, 32-40. https://doi.org/10.1016/j.sbspro.2012.06.540

Sinicrope, C., Norris, J., \& Watanabe, Y. (2007). Understanding and assessing intercultural competence: A summary of theory, research, and practice (technical report for the foreign language program evaluation project). Second Language Studies, 26(1), 1-58.

Straffon, D. A. (2003). Assessing the intercultural sensitivity of high school students attending an international school. International Journal of Intercultural Relations, 27, 487-501. https://doi.org/10.1016/S0147-1767(03)00035-X

Tolo, K. W. (1997). An assessment of "We the People...Project Citizen”: Promoting citizenship in classrooms and communities. Policy Research Reports Series N. 129. Austin, TX: University of Texas at Austin, Lyndon B. Johnson School of Public Affairs.

Vontz, T. S., Metcalf, K. K., \& Patrick, J. J. (2000). "Project Citizen" and the civic development of adolescent students in Indiana, Latvia, and Lithuania. Bloomington, IL: ERIC Clearinghouse for Social Studies/Social Science Education. (ERIC No. 447047)

Walton, J., Paradies, Y., Priest, N., Wertheim, E. H., \& Freeman, E. (2015). Fostering intercultural understanding through secondary school experiences of cultural immersion. International Journal of Qualitative Studies in Education, 28(2), 216-237. https://doi.org/10.1080/09518398.2014.891772

Williams, T. R. (2005). Exploring the impact of study abroad on students' intercultural communication skills: Adaptability and sensitivity. Journal of Studies in International Education, 9(4), 356-371. https://doi.org/10.1177/1028315305277681 